The mean dry matter degradation after 48 hours (DMD 48), largely varied between feeds: $29.3 \%<\mathrm{DMD} 48<96.4 \%$ (SFH, GRK, GRP = from 29 to $45 \%$; BWG, TOP, DLU, WBR $=$ from 65 to $75 \%$; CCM, PKM, WDG, GNM, CGF, PBP, MGM = from 83 to $90 \%$; SPI, SBM, BTP, CIP > $90 \%$ ).

These values were used to estimate the « in vivo » organic matter digestibility with a specific prediction equation obtained from «in vivo" experimental data of the laboratory with 17 concentrates or by-products for ruminants. This procedure allowed to confirm largely the OMD values of some by-products already present in the 1978 INRA table; moreover it permitted to obtain reliable estimations of the OMD values of unknown by-products.

The Acid Detergent Lignin (ADL) content is the analytical parameter which is the most related to the by-product DMD $48:$ DMD $48=88.3-1.25$ ADL $(R=-0.85, \operatorname{RSD}=10.7)$.

Several by-products having a similar DMD 48 value (CIP $=96.4 \%$, BTP $=92.9 \%$ and $\mathrm{SBH}=92.5 \%$; Or PBP $=87.8 \%, \mathrm{GNM}=86.1 \%, \mathrm{MGM}=89.8 \%$ and $\mathrm{CCM}=83.2 \%)$ presented very different levels of dry matter degradation after 12 hours (DMD 12) (CIP $=83.7 \%$ vs $\mathrm{BTP}=74.2 \%$ and $\mathrm{SBH}=52.9 \% ; \mathrm{PBP}=80.6 \%$ and $\mathrm{GNM}=79.7 \%$ vs $\mathrm{MGM}=59.7 \%$ and $\mathrm{CCM}=56.7 \%$ ).

These differences are explained by the large variations in dry matter degradation rate (DMDR) values between 0 and 6 hours (SBH, GRP, GRK, BWG $=$ from 3 to $4.5 \% \mathrm{~h}^{-1} ; \mathrm{PKM}$, CCM, SBH, MGM, CGF, BTP, DLU, TOP = from 5.5 to $7.5 \% \mathrm{~h}^{-1}$; SPI, WDG, WBR, CIP, PBP, GNM $=$ from 8.5 to $11.5 \% \mathrm{~h}^{-1}$ ) and the lack of relationship between the DMD 48 and DMDR values of the feeds.

This latter parameter is more precisely related to the dietary Neutral Detergent Fiber (NDF) content during the first phase of incubation for instance between 0 and 6 hours: DMDR $(0-6)=14.4-0.14$ NDF $(\mathrm{R}=-0.94, \mathrm{RSD}=0.9)$.

This study allowed to obtain data of general interest for ruminants and, on the other hand, useful references in dairy goat feeding.

Key words : By-products, goat, in sacco degradability.

\title{
Digestibility of Atriplex nummularia and Aacacia salicina in goats
}

\author{
J. SILVA-COLOMER *, E. MOLINA, J. FONOLLÁ, J, BOZA \\ Departamento de Fisiología Animal, Estación Experimental del Zaidín (C.S.I.C.), \\ Profesor Albareda, I, 18008 Granada (Spain) \\ * I.A.D.I.Z.A.-C.O.N.I.C.E.T., Mendoza (Argentina).
}

In rangelands of arid areas, browses of shrubs and trees make an important contribution to animal feeding when herbaceous forage is scarce. In this research work the nutritive value of two interesting woody species : Atriplex nummularia (Dry matter, DM : $34.4 \%$; organic matter, OM : $77.4 \%$, acid detergent fibre, ADF : $28.5 \%$, crude protein, CP : $17.0 \%$ ) and Acacia salicina (DM : $32.8 \%$; OM : $83.3 \%$; ADF : $24.5 \%$; CP : $17.3 \%$ ) was studied.

Six Granadina goats were used to determine digestibility « in vivo ». Animals were fed at about a maintenance level a basal diet including pelleted lucerne hay, barley, sunflower cake and a mineral corrector, and a test diet based on equal parts $(50 / 50 \mathrm{DM})$ of the basal diet and Atriplex nummularia or Acacia salicina. They were pre-cutted and oven dried at $70^{\circ} \mathrm{C}$ and then stabilized at environment temperature. The trials of "in vivo " digestibility lasted twenty two days (fifteen days of adaptation to feeding and seven days of faeces collection). Digestibility of Atriplex nummularia and Acacia salicina was obtained by difference. The digestibility " in vitro » was determined following TiLLEY and TERRY's techniques (1963), with ruminal fistulated goats which were fed the basal diet. The solubility with cellulase from Trichoderma viride was obtained according to Aufrere's procedure (1982). We have obtained a simple regression equation from 
data of acid detergent lignine (ADL) content, « in vitro » and « in vivo " digestibility of woody species in order to predict the « in vivo " digestibility of Atriplex nummularia and Acacia salicina.

The " in vivo » digestibility of dry matter (DMD) and organic matter (OMD) of Atriplex nummularia was $57.4 \%$ and $50.4 \%$, respectively. For Acacia salicina, these values were $46.8 \%$ and $48.0 \%$. The " in vitro " values (using ruminal fluid) for those parameters were $57.5 \%$ and $44.9 \%$ (Atriplex) and $54.1 \%$ and $46.0 \%$ (Acacia). In relation with enzymatic solubility (DMS and OMS), the values were $60.6 \%$ and $49.2 \%$ (Atriplex) and $52.1 \%$ and $46.5 \%$ (Acacia).

The simple regressions derived were :

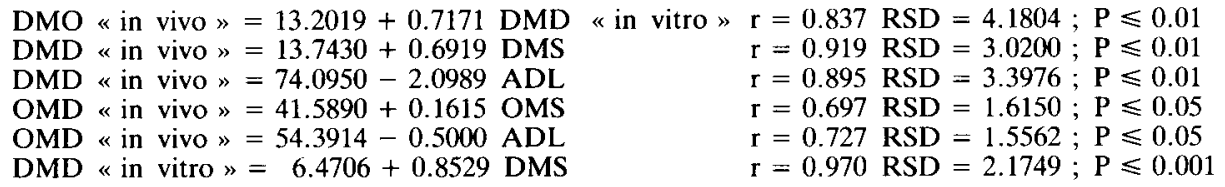

The results obtained show that Atriplex nummularia and Acacia salicina are interesting species to introduce in arid areas for goat feeding.

The provisional regression equations obtained seem to give a correct estimation of the digestibility of the studied species taking into account the high values of the correlation coefficients, levels of significance and the low standard deviations obtained.

Key words : Nutritive value, Atriplex nummularia, Acacia salicina, goat, digestibility.

\section{Digestibility of holm oak (Quercus ilex) fresh foliage in goats : first results}

\section{MEURET}

\section{INRA-S.A.D., Unité d'Ecodéveloppement, Domaine Saint-Paul, 84140 Montfavet (France)}

In Southern France, woodlands are dramatically exposed to fire. Thus, the Forest Managers have planned to reintroduce experimentally some goat herds in the forests to make them participate to the undergrowth-clearing operations. As part of this program, we studied the nutritive value of the main fibrous feeds and their improvement by a suitable complementary feeding. A first trial was made with holm oak (Quercus ilex). Six two-year old goats of the local breed, with a mean live weight of $25 \mathrm{~kg}$, dried since one month and well used to browsing on rangelands were used. Animals were placed in confortable digestibility cages allowing the separate collection of faeces and urine. Cages were specially equipped for distribution of freshly cut branches of trees and shrubs.

From March 19th to April 16th 1986, goats received each day continuously from $10: 30$ a.m. to $07: 00$ p.m. fresh branches cut less than 2 hours before. In addition, animals received each evening a minimum protein supplement of $0.81 \mathrm{~g} \mathrm{DM} / \mathrm{kg} \mathrm{LW}{ }^{0.75}$ soybean meal, corresponding to the protein contribution of the herbaceous species eated on the range. This foraging method allowed us to use the "browsed-class " technique to estimate the intake quality, as a function of the branch type and the rate of consumption of the potential edible matter (P.E.M.) on each branch. Every day, at intervals, many samples of leaves and stems were collected for dry matter determination and chemical analysis.

Results of animal weighings showed a steady increase in the live weight $(100 \mathrm{~g} \mathrm{LW} /$ day) from the 5th day of cages entering to the coming out, indicating real ad libitum feeding conditions. Similar individual choices between branch types and comparable rates of consumption (with a high frequency of the $90 \%$ rate) led to very steady plant part proportions in the individual diets (leaveto-stem ratio $=5.96 \pm 0.13$ ). This composition of the ingested matter was very close to the holm oak mean bite composition recorded on the range with a $10 \mathrm{~A} / \mathrm{ha}$ day stocking density. The chemical composition of the oak diet was $96.3 \%$ Organic Matter, $30.5 \%$ Crude Fibre and $8.3 \%$ Crude Protein. This foraging method with fresh branches led to a high and steady level of intake : $90.1 \pm 3.5 \mathrm{~g} \mathrm{DM} / \mathrm{kg} \mathrm{LW}$. 5 day for a 18 -day period. For this period the following apparent digestibilities were obtained : 